\title{
High Performance Liquid Chromatographic Method for Determination of Clobetasol in Rat Plasma and its Application to Skin Penetration
}

\author{
Prashant B. Musmade', Praful B. Deshpande'1, Swapnil J. Dengle', Kranti B. Talole', Shriram M. Pathak', \\ Adiga MNS ${ }^{2}$, Krishnamurthy Bhat ${ }^{1}$, Nayanabhirama Udupa ${ }^{1}$ and K. Laxminarayana Bairy ${ }^{2 *}$
}

'Dept. of Pharmaceutical Quality Assurance, Manipal College of Pharmaceutical Sciences, Manipal-576104, India ${ }^{2}$ Dept. of Pharmacology, Kasturba Medical College, Manipal-576104, India

\begin{abstract}
A simple and sensitive high performance liquid chromatography (HPLC) method was developed for quantification of clobetasol (CLB) in rat plasma. Aripiprazole was used as an internal standard (IS). The present method uses protein precipitation with acetonitrile, followed by the liquid-liquid extraction with methyl tertiary butyl ether for extraction of the CLB from the matrix. Separation was carried out using Variance $\mathrm{C}_{18}(250.0 \times 4.6$ $\mathrm{mm}, 5 \mu \mathrm{m}$ particle size) column and the effluent was monitored by an ultra violet (UV) detector at $240 \mathrm{~nm}$. The mobile phase used was acetonitrile: phosphate buffer $(\mathrm{pH}$ $7.0 ; 25.0 \mathrm{mM}$ containing $0.2 \% \mathrm{v} / \mathrm{v}$ triethylamine) $(65: 35 \%$ $\mathrm{v} / \mathrm{v})$ at a flow rate of $1.0 \mathrm{ml} / \mathrm{min}$. The present method was validated as per the United States Food and Drug Administration (USFDA) guideline. This method was linear over the range of $25.0-1000.0 \mathrm{ng} / \mathrm{ml}$ with regression coefficient greater than 0.99 . The mean recovery of CLB and IS were $70.8 \pm 1.9$ and $83.32 \pm 1.55 \%$ respectively. The method was found to be precise, accurate and specific. The developed HPLC method was applied for the estimation of CLB in plasma after topical application of various zinc salts in rats to study the penetration of CLB through rat skin.
\end{abstract}

Keywords: Clobetasol; HPLC; Skin penetration; Zinc salt

\section{Introduction}

Psoriasis is a common, chronic, relapsing, genetically determined, inflammatory and proliferative disease of the skin. It affects about 2-3\% of world population. Topical corticosteroids are the most frequently used medication for the treatment of mild-to moderate psoriasis in dermatological practice. These molecules are generally effective, safe, easy to use and relatively inexpensive. Clobetasol (CLB) (Figure 1) being a corticosteroid, widely used for the treatment of psoriasis and other steroid responsive dermatomes (Griffiths et al., 2004; Al-Hamdi et al., 2007; Leopold et al., 1996). Different dosage forms for topical use are currently approved by United States Food and Drug administration (USFDA). For the effective topical treatment of skin diseases and transdermal drug therapy, it is essential that the topically applied drug enters the epidermis or the dermis of the skin and the peripheral blood supply respectively. Skin penetration and permeation of the drug after topical administration depends on the physicochemical properties of the drug molecule and on the function of the skin as a transport barrier and can be influenced by the applied formulation. These factors along with skin first-pass metabolism and the hemodynamic parameters of the cutaneous tissues, determine the bioavailability of topically applied drugs (Mueller et al., 2003; Bach and Lippold, 1998). Few studies indicate that the CLB is absorbed systemically. Some clinical reports claim that the combination of zinc sulphate and clobetasol propionate are better than clobetasol propionate or zinc sulphate alone in conditions like chronic hand eczema and psoriasis (Faghihi et al., 2008).

The present study was planned to evaluate the influence of various zinc salts on penetration of clobetasol propionate creams through rat skin. Eight formulations containing clobetasol propionate $0.05 \% \mathrm{w} / \mathrm{w}$ with Zinc sulphate $1.0 \% \mathrm{w} / \mathrm{w}$, Zinc acetate $0.7 \%$ w/w, Zinc lactate $1.0 \% \mathrm{w} / \mathrm{w}$, Zinc lactate $0.7 \% \mathrm{w} / \mathrm{w}$, Zinc stearate $2.0 \% \mathrm{w} / \mathrm{w}$, Zinc Pyrithione $1.0 \% \mathrm{w} / \mathrm{w}$, nano zinc oxide $0.3 \% \mathrm{w} / \mathrm{w}$ and clobetasol propionate alone were tested. The analysis was carried out by measuring the concentration of clobetasol in plasma after three hours of application of creams.

Although some are reported HPLC methods for quantification of Clobetasol in pharmaceutical formulations such as creams, cosmetic products (Dyderski et al., 2001; Fang et al., 1999; Kamberi et al., 2008; Gagliardi et al., 2000) but these methods are inappropriate for estimation of the CLB in biological fluids. Extensive literature survey did not reveal any suitable method for estimation of CLB in plasma. Thus, in the proposed approach it was planned to develop a simple, sensitive and accurate high

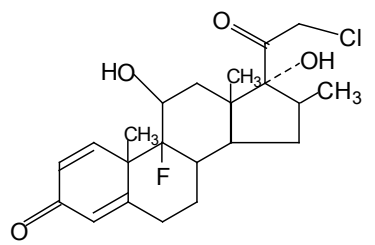

Figure 1: Chemical structure of Clobetasol.

${ }^{*}$ Corresponding author: Dr. K. Laxminarayana Bairy, Dept. of Pharmacology, Kasturba Medical College, Manipal University, Manipal576104, India. Tel:+91 820 2922365; Fax: +91 820 2922083; E-mail: kl.bairy@manipal.edu

Received December 30, 2009; Accepted March 13, 2010; Published March 13, 2010

Citation: Musmade PB, Deshpande PB, Dengle SJ, Talole KB, Pathak SM, et al. (2010) High Performance Liquid Chromatographic Method for the Determination of Clobetasol in Rat Plasma and its Application to Skin Penetration. J Bioanal Biomed 2: 001-007. doi:10.4172/1948-593X.1000013

Copyright: (C) 2010 Musmade PB, et al. This is an open-access article distributed under the terms of the Creative Commons Attribution License, which permits unrestricted use, distribution, and reproduction in any medium, provided the original author and source are credited. 
Citation: Musmade PB, Deshpande PB, Dengle SJ, Talole KB, Pathak SM, et al. (2010) High Performance Liquid Chromatographic Method for the Determination of Clobetasol in Rat Plasma and its Application to Skin Penetration. J Bioanal Biomed 2: $001-007$. doi:10.4172/1948-593X.1000013

performance liquid chromatographic (HPLC) method for estimation of CLB in rat plasma samples. The method was used for estimation of CLB concentration in rat plasma after ointment application. Attempt has been made to study the skin penetration by measuring plasma level of CLB in rat animal model. This method can also be used to study extent of absorption of new formulation of CLB.

\section{Materials and Methods}

\section{Materials}

Clobetasol propionate (CLB) and Aripiprazole (IS) drug samples were supplied by Apex Laboratories Ltd., Chennai, Tamilnadu, India and Torrent Pharmaceutical Ltd., Ahmedabad, Gujarat, India respectively. Acetonitrile and methanol of HPLC grade were purchased from Qualigen India Pvt. Ltd., Mumbai, Maharashtra, India. Analytical grade Potassium dihydrogen Phosphate and Orthophosphoric acid were purchased from Merck Ltd., Mumbai, Maharashtra, India. HPLC grade Triethylamine from Merck Ltd., Mumbai, Maharashtra, India, methyl tert- butyl ether (MTBE) from Spectrochem Ltd., Mumbai, Maharashtra, India were used. All other reagents used were of analytical grade. HPLC-grade water was produced in the laboratory by a Milli-Q purification system (Millipore Corp., Vienna, Austria) and Milli-Q water was used for the preparation of the mobile phase. Disodium Ethylenediamine tetra-acetic acid (EDTA) vacutainers (BD, Franklin Lakes, NJ, USA) used for collection of blood, TurboVap evaporator (Zymark, Hopkinton, MA, USA) was used for evaporation of organic solvent. C24 centrifuge (Remi India, Bangalore, Karnataka, India) used for centrifugation.

\section{Method}

\section{Chromatographic condition}

The HPLC systems consisted of a Waters Alliance 2695 low pressure gradient separation module (Waters Corporation, Milford, MA 01757, USA) with configuration of quaternary solvent delivery pump, sampler cooler, column heater and 2487 dual wavelength UV detector. Chromatographic system operation and recording of data were performed with the use of Millineium software (version 32, Waters Corporation, Milford, MA 01757, USA). The HPLC separation was achieved using a Variance $\mathrm{C}_{18}$ $(250.0 \times 4.6 \mathrm{~mm}, 5 \mu \mathrm{m})$ at $25^{\circ} \mathrm{C}$. The mobile phase was a mixture of acetonitrile: phosphate buffer $(\mathrm{pH} 7.0 ; 25.0 \mathrm{mM}$ containing $0.2 \% \mathrm{v} / \mathrm{v}$ triethylamine) in the ratio of $65: 35 \% \mathrm{v} / \mathrm{v}$. The effluent was monitored with UV detection at $240.0 \mathrm{~nm}$ at a flow rate of $1.0 \mathrm{ml} / \mathrm{min}$. The quantification was accomplished based on the peak area ratio of CLB to IS.

Preparation of the calibration standards and quality control (QC) samples

The stock solutions of CLB and IS were prepared in methanol at a concentration of $1.0 \mathrm{mg} / \mathrm{ml}$ each. The working solutions of 100.0 and $8.0 \mu \mathrm{g} / \mathrm{ml}$ were prepared by appropriately diluting the stock solutions of CLB and IS. CLB working solution was used to prepare the spiking stock solutions in methanol to get the concentration in the range of $250.0-10000.0 \mathrm{ng} / \mathrm{ml}(250.0$, $500.0,750.0,1000.0,2000.0,6000.0,10000.0 \mathrm{ng} / \mathrm{ml})$. The quality control samples i.e. Low Quality Control (LQC), Middle Quality Control (MQC) and High Quality Control (HQC) spiking stock solution were prepared by serial dilution from stock solution to get the concentration of $600.0,1500.0$, and $8000.0 \mathrm{ng} / \mathrm{ml}$ spiking stock solution. Solutions were stored at $2-8^{\circ} \mathrm{C}$ when not in use.

CLB spiking stock solution was used to prepare seven-point calibration standards of 25.0, 50.0, 75.0, 100.0, 200.0, 600.0 and $1000.0 \mathrm{ng} / \mathrm{ml}$ and QC samples at three levels 60.0, 150.0 and $800.0 \mathrm{ng} / \mathrm{ml}$. The bulk volume of calibration standards and QC samples were prepared by spiking 50.0 $\mu$ l of respective spiking working stock solutions to $450.0 \mu \mathrm{l}$ of drug free rat plasma and aliquoted. All these samples were stored at $-70^{\circ} \mathrm{C}$.

\section{Sample preparation for analysis}

The procedure was validated using spiked plasma aliquots 100.0 $\mu$ l. Pooled rat drug-free plasma was obtained from Central animal house facility of Manipal University, Manipal and stored frozen at $-70^{\circ} \mathrm{C} .20 .0 \mu \mathrm{l}$ of IS $(8.0 \mu \mathrm{g} / \mathrm{ml})$ was added to $100.0 \mu \mathrm{l}$ aliquot of plasma (blank, standard or study sample) in a $5.0 \mathrm{ml}$ borosilicate glass tube. The tubes were vortex-mixed for $10 \mathrm{sec}$. Acetonitrile 500.0 $\mu \mathrm{l}$ was added and the tubes vortex mixed for $30 \mathrm{sec}$ to precipitate the plasma proteins. To the same tubes 3.0 $\mathrm{ml}$ of the tetra butyl methyl ether was added and vortexed for $1.0 \mathrm{~min}$. Following centrifugation $(4500 \times g ; 10 \mathrm{~min})$, the clear supernatant organic layer was transferred to a clean glass tube and evaporated to dryness under a stream of nitrogen in a TurboVap evaporator at $40^{\circ} \mathrm{C}$. The residue was reconstituted in $100.0 \mu \mathrm{l}$ of mobile phase, and an aliquot $50.0 \mu \mathrm{l}$ was injected into the HPLC. All procedure for sample preparation was carried out at room temperature.

\section{Method validation}

The method was validated for selectivity and specificity, sensitivity, recovery, linearity, precision, accuracy and stability as per USFDA guidelines.

\section{Selectivity and specificity}

Selectivity and specificity is the ability of the analytical method to differentiate and quantify the analyte in the presence of other expected components in the sample. The absence of chromatographic interference at retention times of the drug and IS from endogenous plasma components was investigated. Six different lots of rat blank plasma samples and set of blanks spiked LLOQ samples concentration were evaluated for selectivity and specificity.

\section{Calibration curve}

Calibration curves were constructed by plotting the peak area ratio of CLB to IS against the nominal concentration of calibration standards. CLB was spiked to blank rat plasma to achieve a range of concentrations 25.0, 50.0, 75.0, 100.0, 200.0, 600.0 and $1000.0 \mathrm{ng} / \mathrm{ml}$ and extracted as per developed sample preparation procedure. The calibration curves used to quantify the CLB concentration in sample. The model for the calibration curve of CLB used the peak area ratio of CLB to IS (y) and the CLB concentration $(\mathrm{x})$, as given in the following equation $\mathrm{y}=$ $\mathrm{mx}+\mathrm{c}$. CLB concentrations were calculated from y using the formula: $\mathrm{x}=(\mathrm{y}-\mathrm{c}) / \mathrm{m}$ where $\mathrm{c}$ is the $\mathrm{y}$ intercept.

The calibration curve should have a correlation coefficient $\left(r_{2}\right)$ of 0.98 for bioanalytical or higher. The acceptance criteria 


\section{Journal of Bioanalysis \& Biomedicine - Open Access JBABM/Vol.2 Issue 1}

for each back-calculated standard concentration was $\pm 15 \%$ deviation from the nominal value except at LLOQ, which was set at $\pm 20 \%$.

\section{Precision and accuracy}

Analyzing six replicates at three different QCs' i.e. 60.0, 150.0 and $800.0 \mathrm{ng} / \mathrm{ml}$, estimated the intra-day assay precision and accuracy. The inter-assay precision was determined by analyzing six replicates at three different QC levels on five different runs. The criteria for acceptability of the data included accuracy within $\pm 15 \%$ deviation from the nominal values and a precision of within $\pm 15 \%$ coefficient of variation (CV), except for LLOQ, where the lowest non-zero concentration level, which could be accurately (relative error $<20 \%$ ) and reproducibly $($ C.V. $<20 \%$ ) determined.

\section{Recovery}

The recovery of CLB and IS through LLE procedure was determined by comparing the peak area of the extracted plasma samples at three QC levels $(n=4)$ with control samples. As controls, equivalent amounts of CLB and the IS were added directly into the mobile phase and injected. Recovery was were determined at low, medium and high concentrations, viz. 60.0, 150.00 and $800.00 \mathrm{ng} / \mathrm{ml}$, whereas the recovery of the IS was determined at a single concentration of $1600.0 \mathrm{ng} / \mathrm{ml}$.

Recovery was assessed by comparing the chromatographic peak area of CLB and IS of the extracted plasma standards to those obtained from equivalent amounts of CLB and IS spiked directly into the mobile phase (corresponding to $100 \%$ recovery). The extraction recovery at each concentration was calculated using the following equation

$$
\text { Recovery }=\frac{\text { Peak area of extracted analyte }}{\text { Peak area of non }- \text { extracted analyte }} \times 100
$$

\section{Stability experiments}

To ensure the reliability of the results in relation to the handling, storing of plasma samples and stock standard solutions, following stability tests were carried out:

1. Short-term stability CLB in rat plasma for period of $6 \mathrm{~h}$ at room temperature.

2. Twenty-four hours autosampler stability of CLB in rat plasma samples extracts at $4^{\circ} \mathrm{C}$.

3. Freeze and thaw stability for three cycles of CLB

4. Long-term stability of CLB in plasma samples stored at $70^{\circ} \mathrm{C}$ for one-month period.

All the stability experiments were carried out at low and high QC concentrations in six replicates. The stability of CLB and IS in injection solvent was determined periodically by injecting replicate preparations of processed samples up to $24 \mathrm{~h}$ (in the autosampler at $4^{\circ} \mathrm{C}$ ) after the initial injection. The peak areas of the CLB and IS obtained at initial cycle were used as the reference to determine the relative stability of the analytes at subsequent points. Stability of CLB in the biomatrix during $6 \mathrm{~h}$ (bench-top) was determined at ambient temperature $\left(22 \pm 2{ }^{\circ} \mathrm{C}\right)$. Analyzing the QC samples stored at $-70^{\circ} \mathrm{C}$ for at least 30 days assessed freezer stability of CLB in rat plasma. The stability of CLB in rat plasma following repeated freeze-thaw cycles was assessed using at three sets of QCs'. The samples were stored at $-70^{\circ} \mathrm{C}$ between freeze-thaw cycles. The stability of CLB was assessed after three freeze-thaw cycles. Each freeze thaw cycle one set of QC is analysed by the proposed method. All the stability experiments were carried out at low and high QC concentrations in six replicates. The samples were processed using the same procedure as described in the sample preparation. All stability evaluations were based on back-calculated concentration from the calibration curves. Samples were considered to be stable if assay values were within the acceptable limits of accuracy (i.e. $\pm 15 \%$ ) and precision (i.e. $\pm 15 \%$ ).

As part of the method validation, stock solution stability was evaluated at room temperature for $6 \mathrm{~h}$ and $2-8^{\circ} \mathrm{C}$ for 15 days, by comparing with freshly prepared stock solution during analysis of the stability samples.

\section{Application of the method for animal study}

The validated method was used to estimate unknown concentration of CLB, obtained from animal study. Forty eight young, healthy, male Wistar rats (divided into eight groups) (Body weight 250-300 g) were obtained from the Central animal house, Manipal University, Manipal and the experimental protocol for the animal studies was approved by the Institutional Animal Ethical Committee. The animals were housed in a polypropylene cages filled with sterile paddy husk and maintained under controlled temperature $\left(25 \pm 2^{\circ} \mathrm{C}\right)$, humidity $(50 \pm 5 \% \mathrm{RH})$ with $12 \mathrm{~h}$ dark and light cycle condition and were acclimatized to laboratory conditions for three days with free access to food and water. The rats were fasted $12 \mathrm{~h}$ before the study.

One day before study animals were shaved an area around $20.0 \times 20.0 \mathrm{~mm}$. Equivalent to $0.2 \mathrm{mg} / \mathrm{kg}$ of ointment was applied to each rat in group of six. Eight different formulations containing clobetasol propionate $0.05 \% \mathrm{w} / \mathrm{w}$ with Zinc sulphate $1.0 \% \mathrm{w} / \mathrm{w}$, Zinc acetate $0.7 \% \mathrm{w} / \mathrm{w}$, Zinc lactate $1.0 \% \mathrm{w} / \mathrm{w}, \mathrm{Zinc}$ stearate $2.0 \% \mathrm{w} / \mathrm{w}$, Zinc Pyrithione $1.0 \% \mathrm{w} / \mathrm{w}$, nano zinc oxide $0.3 \% \mathrm{w} / \mathrm{w}$ and clobetasol propionate alone were applied to an each group.

After $3 \mathrm{~h}$ of application the blood sample was withdrawn through retro orbital plexus in to the sterile Disodium Ethylenediamine tetra-acetic acid (EDTA) vacutainers. Plasma samples were obtained following centrifugation of blood at $3500 \times \mathrm{g}$ for $5 \mathrm{~min}$ at $4^{\circ} \mathrm{C}$ and kept frozen at $-70^{\circ} \mathrm{C}$ until analysis.

\section{Results and Discussion}

Liquid-liquid extraction was tried using various organic solvents like diethyl ether, chloroform, ethyl acetate, dichloromethane, petroleum ether and tetra butyl methyl ether etc as the CLB is hydrophobic in nature. Also combination of these solvents at different ratios had been tried with different precipitating agents. Since the drug was poorly soluble in the above organic solvents, it resulted in poor extraction efficiency. Protein precipitating agents like acids and alkalis were used at different $\mathrm{pH}$ ranges to extract the drug efficiently.

Solid phase extraction can be carried out to achieve the higher extraction efficiency. The extraction efficiency is reproducible when compared to protein precipitation methods and also devoid of interferences. The sensitivity is higher but it is found to be 
Citation: Musmade PB, Deshpande PB, Dengle SJ, Talole KB, Pathak SM, et al. (2010) High Performance Liquid Chromatographic Method for the Determination of Clobetasol in Rat Plasma and its Application to Skin Penetration. J Bioanal Biomed 2: 001-007. doi:10.4172/1948-593X.1000013

expensive. Hence the present study employed protein precipitation method followed by liquid-liquid extraction for extraction of the drug from rat plasma.

The sample preparation step used in this study involved liquidliquid extraction with protein precipitation. The first plasma proteins were precipitated using acetonitrile followed by liquidliquid extraction using methyl tetra butyl ether. This was found to be the most optimal condition for sample preparation as it resulted in a clean chromatogram with good and consistent recovery.

\section{Selectivity and specificity}

The selectivity of the assay was investigated by processing blank rat plasma and recording the chromatogram. No chromatographic interferences derived from endogenous substance were observed in the blank plasma obtained from the rats. Under the described chromatographic conditions, CLB and IS had retention times of about $7.2 \pm 0.2$ and $11.7 \pm 0.2 \mathrm{~min}$, respectively. The chromatographic peaks were resolved to baseline throughout the calibration curve range (25.0-1000.0 $\mathrm{ng} / \mathrm{ml}$ ) studied.

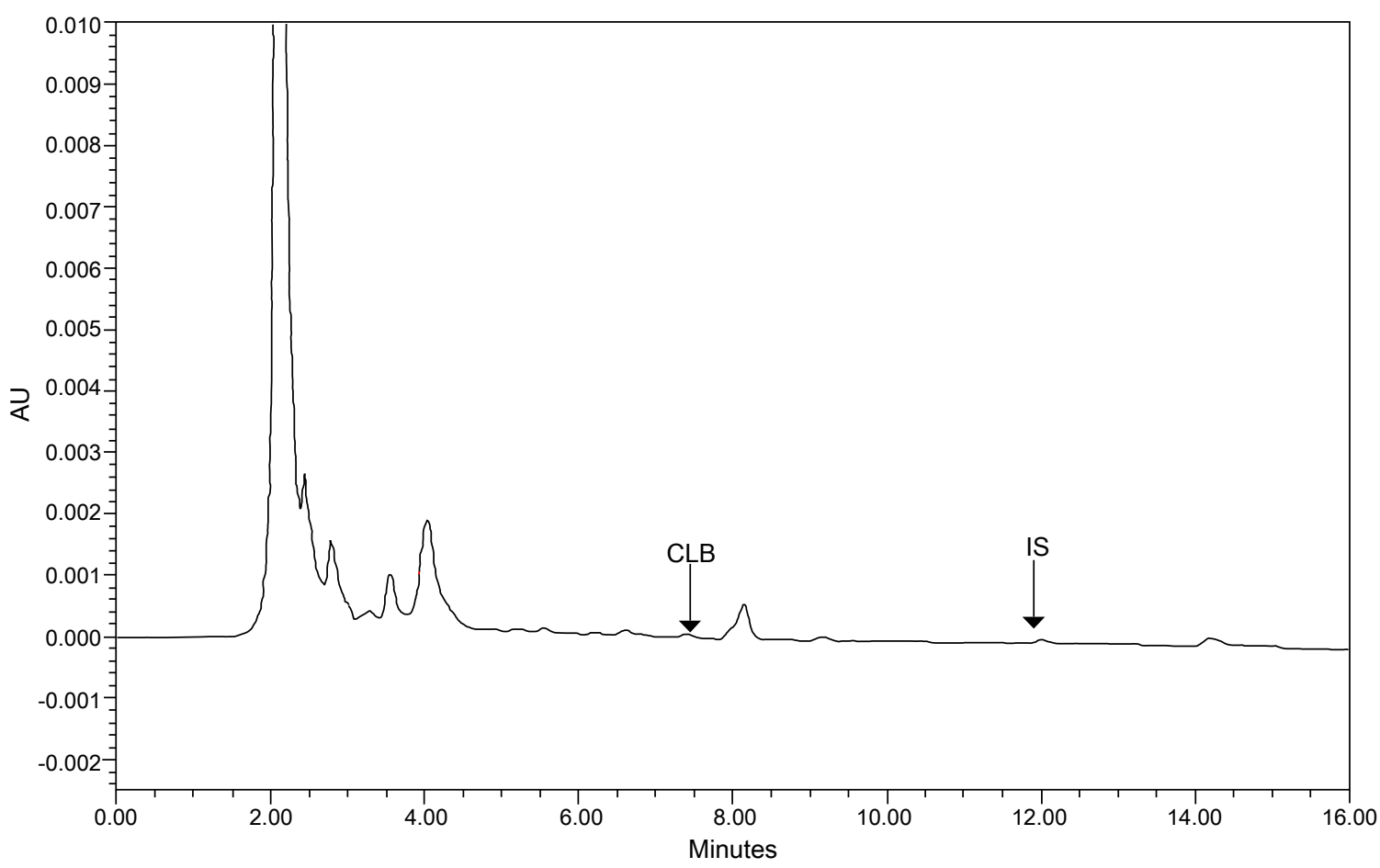

Figure 2: Representative chromatogram of blank rat plasma.

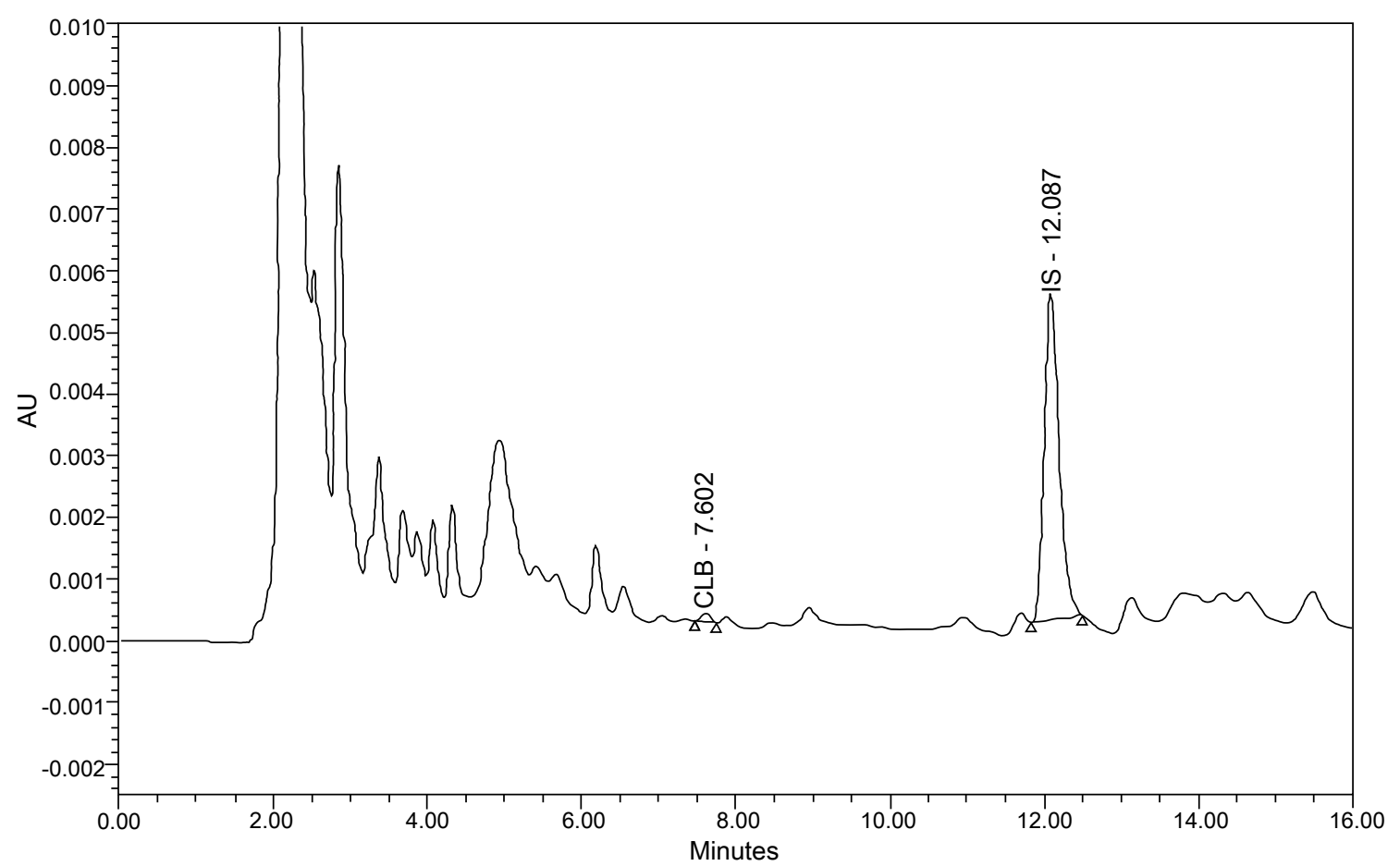

Figure 3: Representative chromatogram of spiked rat plasma at lower limit of quantification of concentration $25.0 \mathrm{ng} / \mathrm{ml}$. 


\section{Journal of Bioanalysis \& Biomedicine - Open Access \\ JBABM/Vol.2 Issue 1}

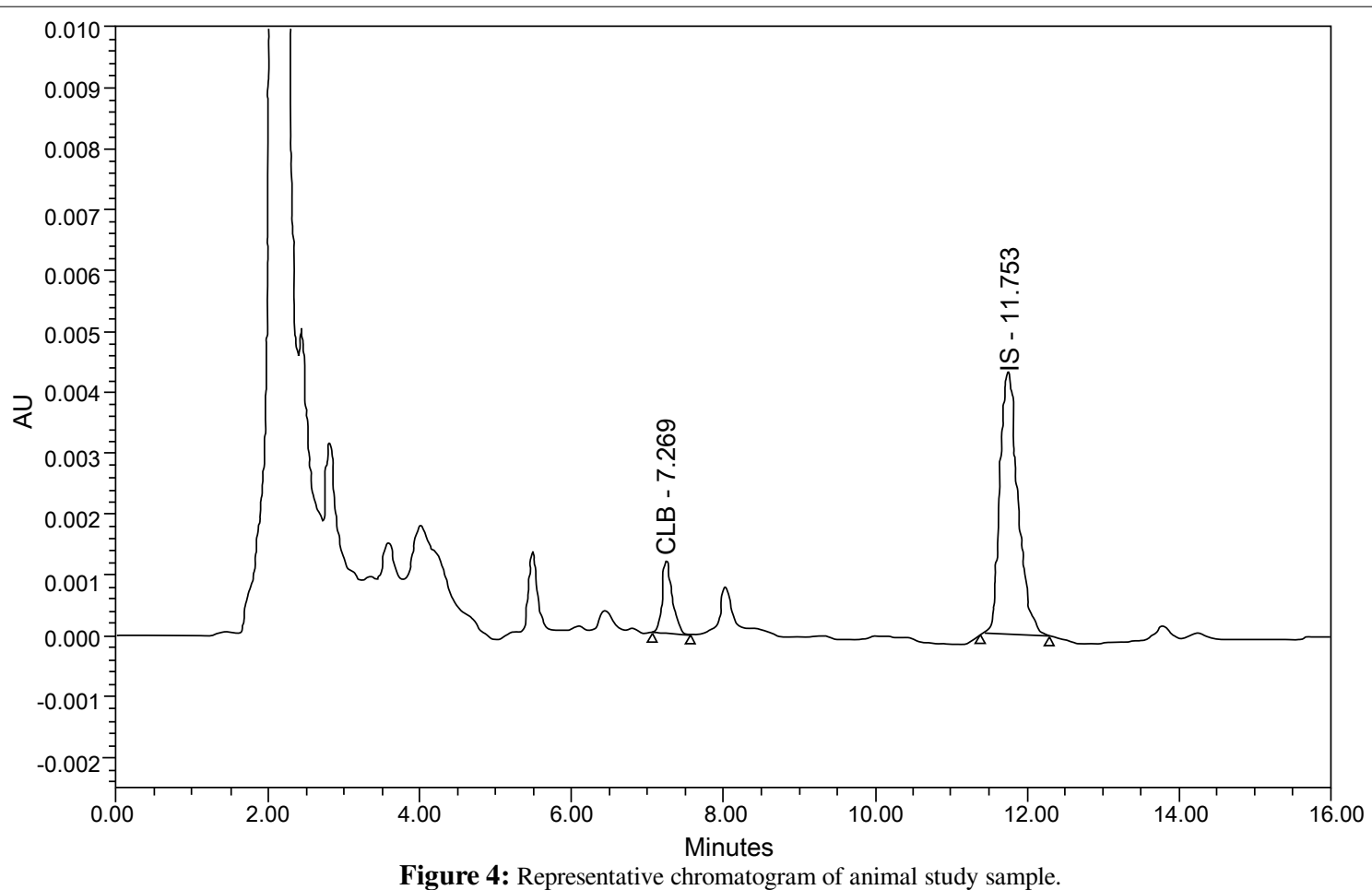

Representative chromatograms of blank rat plasma, LLOQ and one animal study sample containing CLB are shown in Figure 2, Figure 3 and Figure 4 respectively.

The sensitivity experiment was carried out at LLOQ level. The average percentage deviation from the nominal concentration was less than $3.1 \%$ and the precision was within $14.18 \%$ relative standard deviation (R.S.D.).

\section{Linearity}

The plasma calibration curve was constructed using seven point calibration standards covering a concentration range from 25.0-1000.0 $\mathrm{ng} / \mathrm{ml}$. The standard curve had a reliable reproducibility over the standard concentrations across the calibration range. The calibration curve was prepared by determining the best fit of peak-area ratios CLB to IS Vs concentration, and fitted to $\mathrm{y}=\mathrm{mx}+\mathrm{c}$. The average regression $(n=5)$ was found to be $\geq 0.9954$. The lowest concentration with the CV $<20 \%$ was taken as the LLOQ and was found to be 25.0 $\mathrm{ng} / \mathrm{ml}$. The percentage accuracy observed for the mean of backcalculated concentration for five linearities was within 94.61$104.52 \%$, while the precision (\% CV) values ranged from 2.02 to 13.73 . The calibration curve data is given in Table 1 and Table 2.

\section{Precision and accuracy}

Intra- and inter-assay precision and accuracy data are shown in Table 3. It was determined at six replicate injections at each level of LQC, MQC and HQC. The intra-assay R.S.D. at 60.0, 150.0 and $800.0 \mathrm{ng} / \mathrm{ml}$ of CLB was $4.05 \%, 1.07 \%$ and $1.82 \%$ respectively. The inter-assay R.S.D. at the above concentrations was $2.28 \%, 4.85 \%$ and $2.85 \%$ respectively. Accuracy data were also determined and all are within the acceptance interval of 85 $-115 \%$ (Table 3).

Thus, the intra assay and inter-assay accuracy and precision were found to be acceptable for the CLB analysis in support of further pharmacokinetic studies. The data demonstrates the good reproducibility.

\section{Recovery}

The mean relative recovery ( \pm S.D.) of CLB at LQC, MQC, and HQC was $65.8 \pm 2.8 \%, 71.5 \pm 1.6,75.2 \pm 2.0 \%$ respectively. The overall mean recovery of CLB was found to be 70.8 \pm 1.9 . The recovery of IS was found to be $83.32 \pm 1.55 \%$.

\section{Stability}

The stability of the CLB in rat plasma at LQC and HQC level was evaluated. The short-term stability CLB in rat plasma for period of $6 \mathrm{~h}$ on bench top and twenty-four hours autosampler stability of CLB in rat plasma samples extracts at room temperature was evaluated at predicated concentration of 60.0 and $800.0 \mathrm{ng} / \mathrm{ml}$, samples deviated within the acceptable limits from the nominal concentrations (Table 4). Table 4 also shows the results of the analyses of the QC samples (LQC and HQC)

\begin{tabular}{|c|c|c|c|}
\hline $\begin{array}{c}\text { Calibration } \\
\text { curve No. }\end{array}$ & Correlation coefficient $\left(\mathrm{r}^{2}\right)$ & Slope $(\mathrm{m})$ & Intercept(c) \\
\hline 1 & 0.9996 & 0.0011 & 0.0235 \\
\hline 2 & 0.9954 & 0.0012 & 0.0021 \\
\hline 3 & 0.9967 & 0.0012 & 0.0025 \\
\hline 4 & 0.9998 & 0.0011 & 0.0273 \\
\hline 5 & 0.9988 & 0.0008 & 0.0321 \\
\hline
\end{tabular}

Table1: Calibration curve data for CLB $(n=5)$.

\begin{tabular}{|c|c|c|c|c|}
\hline $\begin{array}{c}\text { Calibration } \\
\text { Std (ng/ml) }\end{array}$ & $\begin{array}{c}\text { Mean calculated } \\
\text { Conc.(ng/ml) }\end{array}$ & $\begin{array}{c}\text { \%deviation } \\
\text { From } \\
\text { nominal } \\
\text { value }\end{array}$ & $\%$ CV & $\%$ Accuracy \\
\hline 25.00 & $23.65 \pm 3.25$ & -5.39 & 13.7 & 94.6 \\
\hline 50.00 & $50.05 \pm 3.96$ & 0.10 & 7.9 & 100.1 \\
\hline 75.00 & $76.86 \pm 5.72$ & 2.48 & 7.4 & 102.5 \\
\hline 100.00 & $97.58 \pm 8.03$ & -2.42 & 8.2 & 97.6 \\
\hline 200.00 & $209.04 \pm 4.21$ & 4.52 & 2.0 & 104.5 \\
\hline 600.00 & $574.44 \pm 13.26$ & -4.26 & 2.4 & 95.7 \\
\hline 1000.00 & $1009.38 \pm 50.59$ & 0.94 & 5.0 & 100.9 \\
\hline
\end{tabular}

Table2: Calibration curve mean data $(\mathrm{n}=5)$. 
Citation: Musmade PB, Deshpande PB, Dengle SJ, Talole KB, Pathak SM, et al. (2010) High Performance Liquid Chromatographic Method for the Determination of Clobetasol in Rat Plasma and its Application to Skin Penetration. J Bioanal Biomed 2: 001-007. doi:10.4172/1948-593X.1000013

\begin{tabular}{|l|l|l|l|l|}
\hline $\begin{array}{l}\text { Nominal } \\
\text { Concentration }(\mathrm{ng} / \mathrm{ml})\end{array}$ & $\begin{array}{l}\text { No. of } \\
\text { replicates }\end{array}$ & $\begin{array}{l}\text { Estimated concentration } \\
(\mathrm{ng} / \mathrm{ml}) ; \text { mean } \pm \text { S.D. }\end{array}$ & $\begin{array}{l}\text { Precision } \\
(\% \text { R.S.D. })\end{array}$ & \\
\hline Intra-assay & & & \\
\hline 60.0 & 6 & $60.82 \pm 2.46$ & 4.05 \\
\hline 150.0 & 6 & $147.93 \pm 1.58$ & 1.07 \\
\hline 800.0 & 6 & $7.89 \pm 14.34$ & $101.37 \pm 4.11$ \\
\hline Inter-assay & & & $98.17 \pm 1.05$ \\
\hline 60.0 & 6 & $61.81 \pm 1.41$ & & \\
\hline 150.0 & 6 & $147.47 \pm 7.15$ & & \\
\hline 800.0 & 6 & $787.07 \pm 22.41$ & 2.28 & \\
\hline
\end{tabular}

Table 3: Intra and inter-assay and accuracy of the assay for clobetasol (CLB) in plasma.

\begin{tabular}{|c|c|c|c|c|}
\hline Stability & $\begin{array}{l}\text { Spiked concentration } \\
(\mathrm{ng} / \mathrm{ml})\end{array}$ & $\begin{array}{l}\text { Average calculated } \\
\text { comparison sample } \\
\text { concentration }(\mathrm{ng} / \mathrm{ml})\end{array}$ & $\begin{array}{l}\text { Average calculated stability } \\
\text { sample concentration } \\
(\mathrm{ng} / \mathrm{ml})\end{array}$ & Average percentage $(\%)$ \\
\hline \multirow[t]{2}{*}{ Bench top $^{a}$} & 60.0 & $64.08 \pm 1.95$ & $63.07 \pm 3.08$ & 98.43 \\
\hline & 800.0 & $784.86 \pm 13.94$ & $777.94 \pm 13.90$ & 99.12 \\
\hline \multirow[t]{2}{*}{ Autosampler $^{b}$} & 60.0 & $60.34 \pm 4.86$ & $59.21 \pm 4.58$ & 98.12 \\
\hline & 800.0 & $790.33 \pm 13.11$ & $788.05 \pm 16.86$ & 99.71 \\
\hline \multirow[t]{2}{*}{ Freeze and thaw ${ }^{\mathrm{c}}$} & 60.0 & $61.17 \pm 3.69$ & $60.34 \pm 4.66$ & 98.64 \\
\hline & 800.0 & $786.09 \pm 14.73$ & $774.92 \pm 17.05$ & 98.58 \\
\hline \multirow[t]{2}{*}{ Long term ${ }^{\mathrm{d}}$} & 60.0 & $60.34 \pm 4.86$ & $58.97 \pm 3.75$ & 97.74 \\
\hline & 800.0 & $790.33 \pm 13.11$ & $771.83 \pm 15.61$ & 97.62 \\
\hline
\end{tabular}

Where a-after $6 \mathrm{~h}$ at room temperature; b-after $24 \mathrm{~h}$ at $4{ }^{\circ} \mathrm{C}$; c- after 3 freeze and thaw cycles at $-70^{\circ} \mathrm{C}$; c- at $-70^{\circ} \mathrm{C}$ for 30 days.

Table4: Stability sample results for CLB $(n=5)$.

\begin{tabular}{|l|l|l|}
\hline Sr. No & Formulation & Concentration of CLB(ng/ml) \pm S.D. \\
\hline 1 & Clobetasol propionate $0.05 \% \mathrm{w} / \mathrm{w}$ & $106.03 \pm 17.7$ \\
\hline 2 & Clobetasol propionate $0.05 \% \mathrm{w} / \mathrm{w}+$ Zinc sulphate $1.0 \% \mathrm{w} / \mathrm{w}$ & $144.83 \pm 12.77$ \\
\hline 3 & Clobetasol propionate $0.05 \% \mathrm{w} / \mathrm{w}+$ Zinc oxide $0.3 \% \mathrm{w} / \mathrm{w}$ & $196.81 \pm 14.04$ \\
\hline 4 & Clobetasol propionate $0.05 \% \mathrm{w} / \mathrm{w}+$ Zinc acetate $0.7 \% \mathrm{w} / \mathrm{w}$ & $164.1 \pm 22.61$ \\
\hline 5 & Clobetasol propionate $0.05 \% \mathrm{w} / \mathrm{w}+$ Zinc lactate $1.0 \% \mathrm{w} / \mathrm{w}$ & $206.6 \pm 14.79$ \\
\hline 6 & Clobetasol propionate $0.05 \% \mathrm{w} / \mathrm{w}+$ Zinc stearate $2.0 \% \mathrm{w} / \mathrm{w}$ & $126.51 \pm 13.8$ \\
\hline 7 & Clobetasol propionate $0.05 \% \mathrm{w} / \mathrm{w}+$ Zinc Pyrithione $1.0 \% \mathrm{w} / \mathrm{w}$ & $166.85 \pm 15.1$ \\
\hline 8 & Clobetasol propionate $0.05 \% \mathrm{w} / \mathrm{w}+$ nano zinc oxide $0.3 \% \mathrm{w} / \mathrm{w}$ & $107.60 \pm 9.04$ \\
\hline
\end{tabular}

Table 5: Concentration Clobetasol formulation in animal samples.

following three repeated freeze-thaw cycles and long term stability of CLB in rat plasma at $-70^{\circ} \mathrm{C}$. Result show that CLB was stable at all conditions studied.

\section{Determination of the concentration of the CLB in unknown sample}

The aim of the present method was estimation of the extent of CLB absorbed to the blood after topical application. The level of the CLB indicates extent of the penetration through skin. The CLB ointment was applied to shaved portion to rat. After $3 \mathrm{~h}$ of application the blood sample was withdrawn and plasma was separated. The collected plasma samples were process as per sample preparation procedure. The all eight formulations containing clobetasol propionate $0.05 \% \mathrm{w} / \mathrm{w}$ with Zinc sulphate $1.0 \% \mathrm{w} / \mathrm{w}$, Zinc acetate $0.7 \% \mathrm{w} / \mathrm{w}$, Zinc lactate $1.0 \% \mathrm{w} / \mathrm{w}$ Zinc lactate $0.7 \% \mathrm{w} / \mathrm{w}$, Zinc stearate $2.0 \% \mathrm{w} / \mathrm{w}$, Zinc Pyrithione $1.0 \%$ w/w, nano zinc oxide $0.3 \% \mathrm{w} / \mathrm{w}$ and clobetasol propionate applied to each group containing six rats. The samples obtained from rats were analysed by developed HPLC method and results were shown in Table 5.

\section{Conclusion}

In conclusion, a simple, rapid, sensitive, specific, accurate and reproducible reversed phase HPLC method for the determination of clobetasol in rat plasma was developed. Protein precipitation method followed by liquid-liquid extraction for extraction of the drug from rat plasma was adopted. The developed method was successfully applied to the study of penetration of clobetasol from different zinc salts in rat for the first time. The method is also proficient in determination of large number of biological samples. The results indicated that absorption of clobetasol propionate $0.05 \% \mathrm{w} / \mathrm{w}$ with zinc lactate $1.0 \% \mathrm{w} / \mathrm{w}$ more compared with other zinc salts and Clobetasol alone.

\section{Acknowledgement}

We gratefully acknowledge the generosity of Apex Laboratories Ltd., Chennai, Tamil Nadu, India for supply of the Clobetasol standard.

\section{References}

1. Al-Hamdi KI, Al-Waiz, Al-Kinani MM, Al-Kinani LC (2007) Treatment of psoriasis with zinc sulphate cream $2.5 \%$ in comparison with Clobetasol propionate cream. Int J Dermatol 5. » CrossRef » PubMed » Google Scholar

2. Bach M, Lippold BC (1998) Percutaneous penetration enhancement and its quantification. Eur J Pharm Biopharm 46: 1-13. » CrossRef » PubMed » Google Scholar

3. Dyderski S, Grześkowiak E, Szałek E, Mrzygłód A (2001) Pharmaceutical availability of clobetasol-17-propionate from cream and ointment. Acta Pol Pharm 58: 435-438. » CrossRef » PubMed » Google Scholar

4. Faghihi G, Iraji F, Shahingohar A, Saidat A (2008) The efficacy of $0.05 \%$ Clobetasol $+2.5 \%$ zinc sulphate cream vs. $0.05 \%$ Clobetasol alone cream in the treatment of the chronic hand eczema: a double-blind study. J Eur Acad Dermatol Venereol 22: 531-536. CrossRef » PubMed » Google Scholar

5. Fang JY, Shen KL, Huang YB, Wu PC, Tsai YH (1999) Evaluation of topical J Bioanal Biomed
Volume 2(1) : 001-007 (2010) - 006 


\section{Journal of Bioanalysis \& Biomedicine - Open Access JBABM/Vol.2 Issue 1}

application of Clobetasol 17-propionate from various cream bases. Drug Dev Ind Pharm 25: 7-14. » CrossRef » PubMed » Google Scholar

6. Food and Drug Administration (2001) FDA Guidance for Industry Bioanalytical Method Validation. Rockville, MD: US Department of Health and Human Services, Food and Drug Administration, Center for Drug Evaluation and Research. »CrossRef » PubMed » Google Scholar

7. Franz TJ, Lehman PA, Feldman SR, Spellman MC (2003) Bioavailability of clobetasol propionate in different vehicles. Skin Pharmacol Appl Skin Physiol 16: 212-216. »CrossRef » PubMed » Google Scholar

8. Gagliardi L, De Orsi D, Manna F, Tonelli D (2000) HPLC determination of clobetasol propionate in cosmetic products. J Liq Chrom and rel Technol 23: 355-362. »CrossRef » PubMed » Google Scholar

9. Griffiths CEM, Camp RDR, Baker JNW (2004) Psoriasis, In: Tony Burns, Breathnach, Cox, Griffiths. Rooks Text book of Dermatology.7th Ed London; Blackwell Ltd 35: 35-69. » CrossRef » PubMed » Google Scholar

10. Kamberi M, Fu K, Lu J, Chemaly GM, Feder D (2008) A sensitive high-throughput HPLC assay for simultaneous determination of everolimus and clobetasol propionate. J Chromatogr Sci 46: 23-29. » CrossRef » PubMed » Google Scholar
11. Leopold CS, Maibach HI (1996) Effect of lipophilic vehicles on in vivo skin penetration of methyl nicotinate in different races. Int J pharm 139: 161-167. »CrossRef » PubMed » Google Scholar

12. Mueller B, Anissimov YG, Roberts MS (2003) Unexpected clobetasol propionate profile in human stratum corneum after topic. Pharma Res 20: 1835-1837. »CrossRef » PubMed » Google Scholar

13. Shah VP (2007) The History of Bioanalytical Method Validation and Regulation: Evolution of a Guidance Document on Bioanalytical Methods Validation. The AAPS Journal 9: E43-E47. » CrossRef » PubMed » Google Scholar

14. Weigmann HJ, Lademann J, Schanzer S (2001) Correlation of the local distribution of topically applied substances inside the stratum corneum determined by tape-stripping to differences in bioavailability. Skin Pharmacol Appl Skin Physiol 14: 98-102.»CrossRef » PubMed » Google Scholar

15. Weigmann H, Lademann J, Pelchrzim R (1999) Bioavailability of clobetasol propionate-quantification of drug concentrations in the stratum corneum by dermatopharmacokinetics using tape stripping. Skin Pharmacol Appl Skin Physiol 12: 46-53. »CrossRef » PubMed » Google Scholar 